\title{
Philosophiques
}

\section{Illustration : Francis Bacon, Tryptique d'août 1972}

Volume 23, numéro 1, printemps 1996

Critères esthétiques et métamorphoses du beau

URI : https://id.erudit.org/iderudit/027366ar

DOI : https://doi.org/10.7202/027366ar

Aller au sommaire du numéro

Éditeur(s)

Société de philosophie du Québec

ISSN

0316-2923 (imprimé)

1492-1391 (numérique)

Découvrir la revue

Citer ce document

(1996). Illustration : Francis Bacon, Tryptique d'août 1972. Philosophiques, 23(1),

66-66. https://doi.org/10.7202/027366ar d'utilisation que vous pouvez consulter en ligne.

https://apropos.erudit.org/fr/usagers/politique-dutilisation/ 
PHILOSOPHIQUES

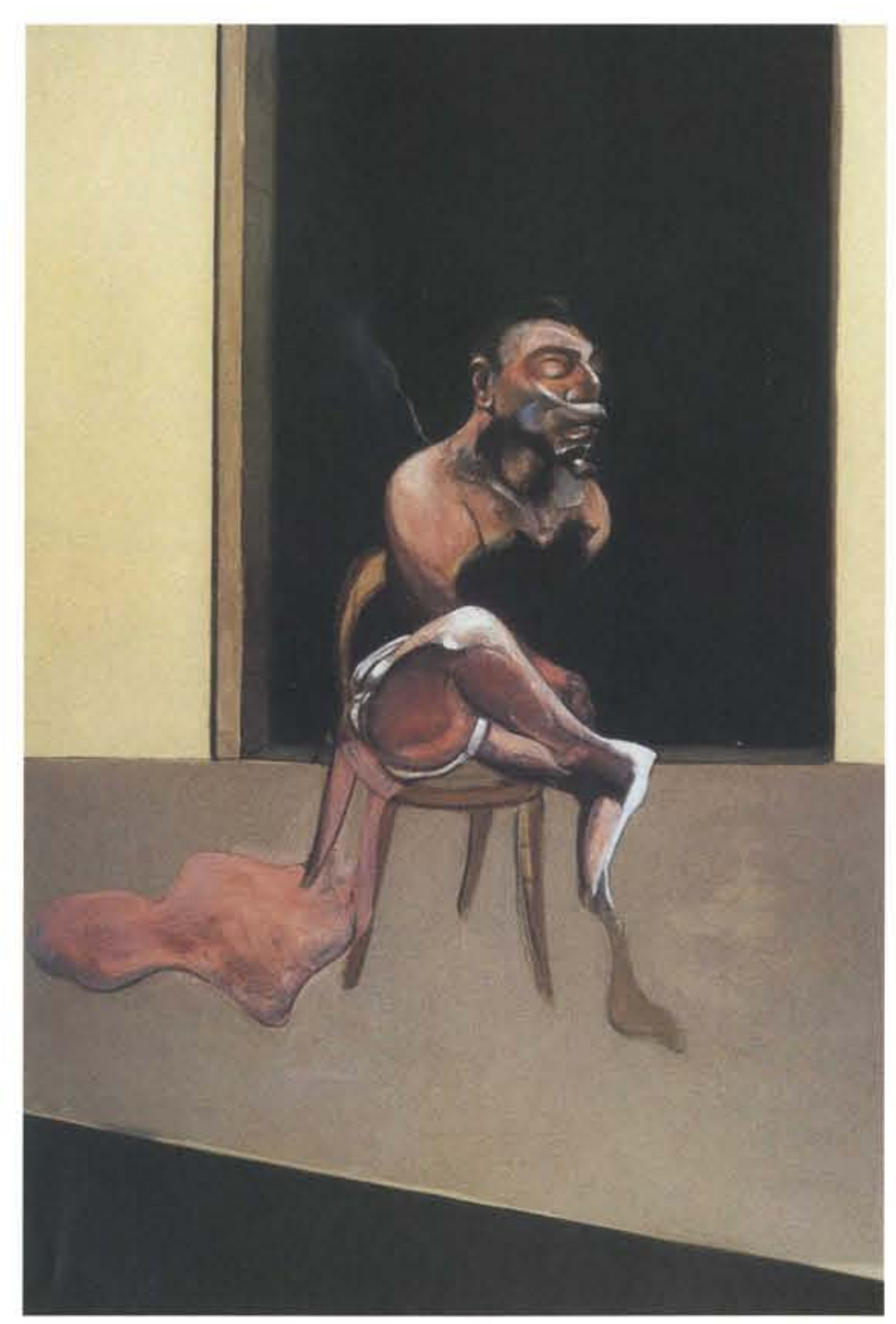

Francis Bacon, Tryptique d'août, 198 x $147,5 \mathrm{~cm}$. o Marlborough Fines

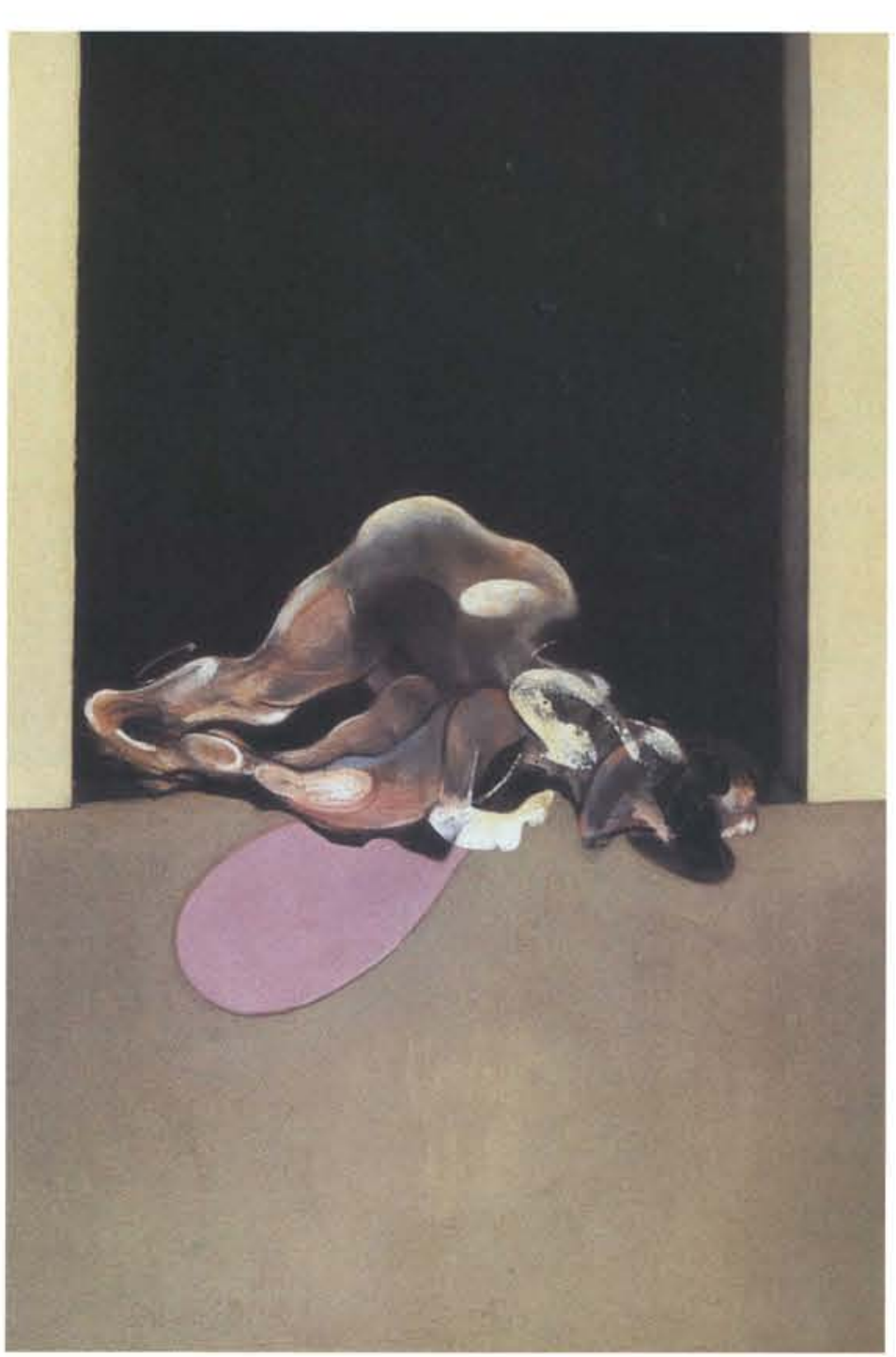

Francis Bacon, Tryptique d'août, 198 x $147,5 \mathrm{~cm}$. $\odot$ Marlborough Fine Art

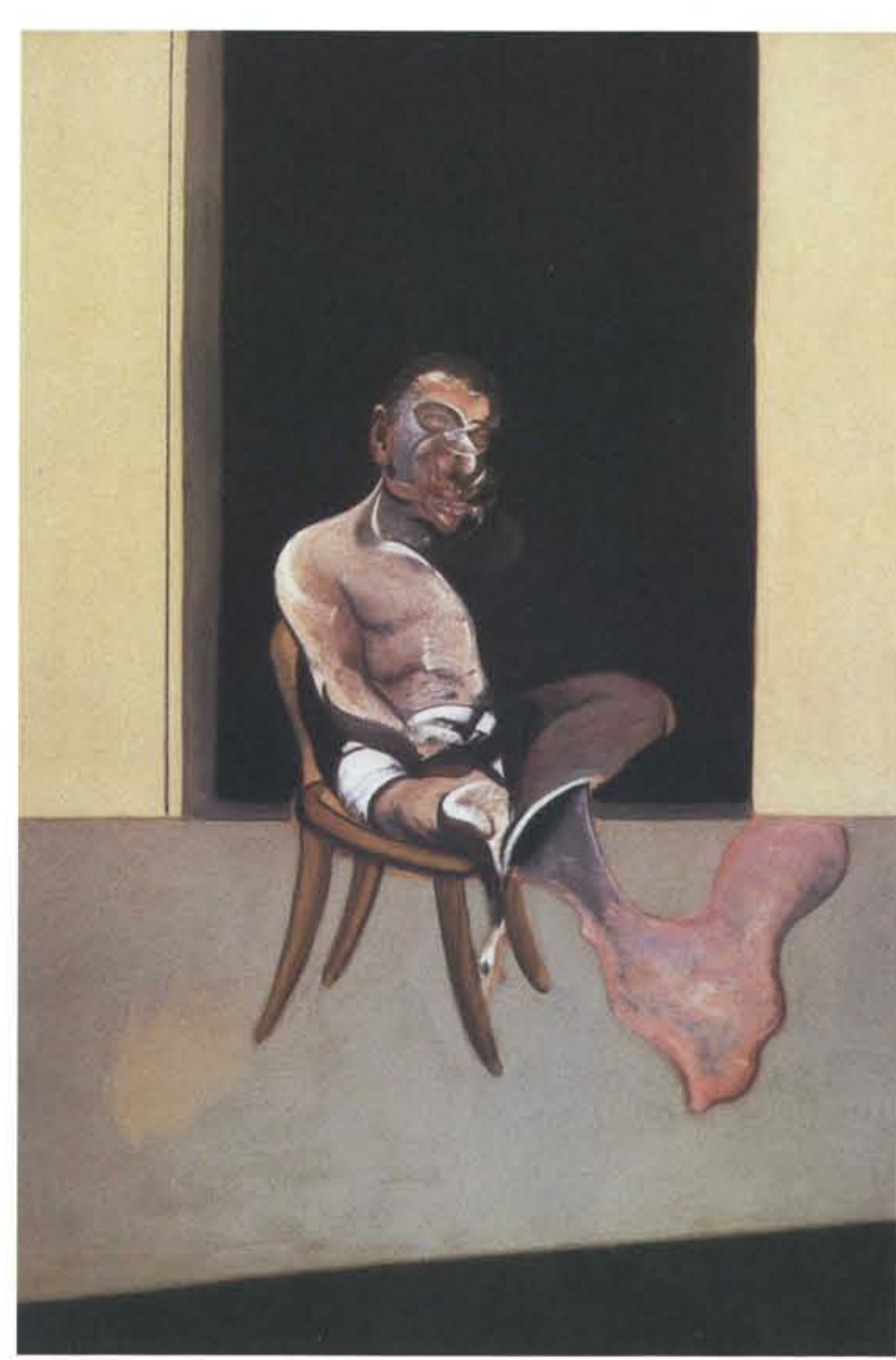

Francis Bacon. Tryptique d'août, 198 x $147,5 \mathrm{~cm}$ O Marlborough Fine Ar 